Research Article

\title{
Paste Pipeline Transportation of Pumping Backfill Technology with Long Distance and High Stowing Gradient in Cold and High-Altitude Areas
}

\author{
Wei-jun Liu $\mathbb{D}^{1,2}$ Min Chen, ${ }^{3}$ Fei-fei Wang, ${ }^{1,2}$ Ren-ze Ou, ${ }^{1,2}$ and Qi Liu ${ }^{1,2}$ \\ ${ }^{1}$ Changsha Institute of Mining Research Co., Ltd, Changsha 410012, China \\ ${ }^{2}$ State Key Laboratory of Safety Technology of Metal Mines, Changsha 410012, China \\ ${ }^{3}$ Business School, Hunan Institute of Technology, Hengyang 421002, China \\ Correspondence should be addressed to Wei-jun Liu; 1552094009@qq.com
}

Received 9 September 2021; Accepted 26 November 2021; Published 17 December 2021

Academic Editor: Qibin Lin

Copyright (C) 2021 Wei-jun Liu et al. This is an open access article distributed under the Creative Commons Attribution License, which permits unrestricted use, distribution, and reproduction in any medium, provided the original work is properly cited.

A paste pipeline transportation of pumping backfill technology with long distance and high stowing gradient is proposed to solve the problem of filling slurry transportation with low concentration, the filling body poor quality, and the transportation difficulties with long distance and high stowing gradient in Heiniudong copper mine (HCM). The physical and chemical properties of the backfill material, backfill proportion test, circular pipe experiment, and backfill system analysis evaluation were studied in the laboratory and outdoor, and the application in HCM was carried out to evaluate the technology. The research results show the feasibility of considering classified tailings and binder as backfill aggregates, and the optimum proportion of cement-binderclassified tailings applied in the stope and goaf is $1: 4: 8$ and $1: 4: 15$, respectively, with paste rheological properties of mass fractions of both being $74 \% \sim 76 \%$ and the backfill strength of about $1.5 \mathrm{MPa}$ at $28 \mathrm{~d}$. Furthermore, when backfill proportions and rate of flow are $1: 4: 8$ and $50 \mathrm{~m}^{3} / \mathrm{h}$, the pressure loss of the pipeline is around $0.4 \mathrm{MPa} / 100 \mathrm{~m}$, and the backfill pump meets the backfill requirements. On this condition, the technology is capable of obvious economic benefits with the backfill cost of only 25.56 yuan/t, remnant ore recovery rate of $80 \%$, and new output value of 1.28 billion. It creates a precedent for the paste pumping backfill technology with long distance and high stowing gradient in cold and high-altitude areas. The technology also provides reference mining experience for similar mines.

\section{Introduction}

With the development of mining industry and depletion of shallow resources, a large amount of domestically residual ore resources and excessive mined-out areas in shallow have been produced. Meanwhile, a huge amount of tailings are generated in the mining process. The deposition of these tailings requires a lot of land and brings about serious environmental problems [1]. For instance, nearly 250 million tons of waste rock and 500 million tons of tailings are produced in China annually. In addition, a large amount of domestically residual ore resource recycling is very important to many mines, and the mined-out areas existing in underground can easily cause geotechnical and environmental hazards, such as underground subsidence, stope, and regional instability [2]. Thus, the best way to deal with the problem is to utilize the tailings as a backfill material, returning them to mined-out areas through the cemented backfill technology (CBT) [3]. CBT plays a key role in the underground mining procedure. There are many different types of mining CBT, such as cemented hydraulic, rock, and paste backfill. And they have been widely used in many mines [4]. However, in the practical application of cemented backfill technology (CBT), a key problem is how to use the technology of pipeline transportation for transporting the backfill materials into the mined voids. In cemented backfill technology, self-flowing pipeline transportation backfill technology and the pumping backfill technology have been used widely and successfully in many mines in Australia, Canada, Europe, and other countries, only by taking the 
advantage of large elevation difference alone, namely, small stowing gradient, in slurry backfill industry. But the longdistance pipeline transportation with high stowing gradient is still an enormous challenge facing by the backfill system in many mines. Particularly, it is still a new technology in China. Nevertheless, domestically, the research on the paste pumping backfill system concerning long-distance pipeline transportation with high stowing gradient has been rarely concerned $[5,6]$. Therefore, the relevant scholars and operators do a lot of exploratory research on the problem $[7,8]$. On the issues, a paste-like self-flowing pipeline transportation backfill technology with long-distance pipeline transportation and high stowing gradient has been proposed to solve the difficult problems of deep mining in the Suncun Coal Mine (SCM) in 2008, and the backfill results have been proved to be effective [9].

Heiniudong copper mine (HCM) is located in the south of Jiulong County, Ganzi Tibetan Autonomous Prefecture, Sichuan Province. The main ore resources are copper and zinc, and the elevation of the mine is $2900 \sim 4000 \mathrm{~m}$, which belongs to a typical cold and high-altitude area. At present, the upper mining area carries out residual mining and recovery, and the reserve of residual hole resources is rich, and it mainly uses the backfilling method to recover residual ores. In order to better recover residual ore resources, the existing backfilling system of the mine needs to meet the following conditions: the mass concentration of slurry needs to exceed $72 \%$, and the filling capacity must be greater than $50 \mathrm{~m}^{3} / \mathrm{h}$. The stowing gradient of the Heiniudong copper mine must be greater than 10 , the range of gravity transportation of backfilling slurry must be small, and the backfilling slurry of most goaves must be transported under pressure. Therefore, in order to maximize the recovery of residual hole resources, pumping backfill technology (PBT) is the best choice for HCM.

Hence, a paste pipeline transportation of pumping backfill technology (PBT) with long distance and high stowing gradient is proposed as a processing method at HCM [9]. The backfilling rheological properties are similar to cemented paste backfill (CPB) with mass fractions of $74 \% \sim 76 \%$ and also the technology has the characteristics of low cost, large capacity, high recovery, and environmental protection. Therefore, this paper focuses on the application of PBT in HCM. To achieve the goal, the paper is organized as follows: the paper presented the backfill material characteristics and the laboratory methods used by backfill material sampling tests and laboratory tests. After that, through the proportion test, the optimization proportion of the paste is identified. Finally, the circular pipe test and analysis of the backfill system are all used to evaluate the rationality of the technology. In the study, the technology meets the requirements of backfilling capability and safety with long distance and high stowing gradient in SCM. Furthermore, the technology features of reliability and stability are developed.

\section{The Backfill Material and Tests}

2.1. Requirements on the Backfill Materials. Binder, classified tailings, slag, water, and other industrial wastes are usually used in the main backfilling material $[10,11]$.

\subsection{The Physical and Chemical Properties of Backfill Material.} The classified tailings from HCM are selected as a backfill aggregate. The bagged cement is used as a cementing material, the binder is added as an activator, and water is mixed with the binders and classified tailings.

The physical properties and chemical composition of backfill materials will affect the filling process parameters and pollute the underground working environment if they contain harmful ingredients. Therefore, the main physical and mechanical properties, chemical composition, and content of backfill materials should be measured accurately.

Specific gravity tests of coarse aggregate were undertaken according to the specific gravity flask method. The dry density test was performed by using a small gravimeter. The hydraulic conductivity test was conducted according to ASTM D2734-68 (2014), and the constant head method was used to measure the water conductivity. The particle size distribution of backfill materials was studied through screening analysis based on the combined screening method and the proportion analysis method. The determination of chemical composition of the tailing test was conducted according to TP-BS6H (2014). The results are shown in Tables 1 and 2.

\subsubsection{Characteristics of Backfill Material}

(1) The main physical properties of classified tailings and binder are listed in Table 1. As shown in Table 1, the specific gravity of the classified tailings is 2.46 , the porosity is $0.51 \sim 0.59 \mathrm{~mm}$, and particle size of the classified tailings is $0.17 \mathrm{~mm}$, respectively, and the high permeability coefficient $(198.5 \mathrm{~mm} / \mathrm{h})$ is much higher than the required $100 \mathrm{~mm} / \mathrm{h}$. The initial setting time is short, making it an ideal aggregate. The graded tailings particles are well distributed, and the asymmetry index 7.5 is greater than 5 , which is conducive to promoting the initial strength of the backfill body.

(2) The size grading of the classified tailings is shown in Table 2, and the grain size distribution curves of the backfill material used are shown in Figure 1. It can be seen that the tailing particle size is fine-grained from the tailing particle size distribution (Figure 1). The percentage of classified tailing particles with a size smaller than $0.25 \mathrm{~mm}$ accounts for $60.86 \%$, which contributes to the coagulation of the paste-like backfill body. 
TABLE 1: Main physical properties of classified tailings and binders.

\begin{tabular}{|c|c|c|c|c|c|c|c|c|}
\hline Material & Special gravity & $\begin{array}{l}\text { Bulk density } \\
\quad\left(\mathrm{t} \cdot \mathrm{m}^{-3}\right)\end{array}$ & Void ratio & $\begin{array}{l}\text { Mediate } \\
\text { size }(\mathrm{mm})\end{array}$ & $\begin{array}{l}\text { Asymmetry } \\
\text { index }\end{array}$ & $\begin{array}{l}\text { Angle of rest } \\
\text { in water }\left({ }^{\circ}\right)\end{array}$ & $\begin{array}{l}\text { Angle } \\
\text { of } \\
\text { repose } \\
\text { on } \\
\text { water } \\
\left(^{\circ}\right)\end{array}$ & $\begin{array}{c}\text { Hydraulic } \\
\text { conductivity }\left(\mathrm{cm} \cdot \mathrm{s}^{-1}\right)\end{array}$ \\
\hline Classified tailings & 2.46 & 1.34 & $0.51-0.59$ & 0.17 & 7.2 & 31.5 & 32.9 & $59.1 \times 10^{-4}$ \\
\hline Binder & 2.25 & 0.91 & $0.49-1.31$ & 0.02 & 2.19 & 15 & 17 & $1.23 \times 10^{-4}$ \\
\hline
\end{tabular}

TABLE 2: Gradation of classified tailings particle size (\%).

\begin{tabular}{lccccccc}
\hline Material & \multicolumn{5}{c}{ Size $(\mathrm{mm})$} \\
& $5 \sim 2$ & $2 \sim 0.5$ & $0.5 \sim 0.25$ & $0.25 \sim 0.075$ & $0.075 \sim 0.05$ & $0.05 \sim 0.005$ & $<0.005$ \\
\hline Classified tailings & 0.24 & 11.2 & 27.7 & 38.2 & 9.3 & 7.5 \\
Binder & 0.53 & 2.13 & 2.4 & 10.7 & 8.5 & 72 \\
\hline
\end{tabular}

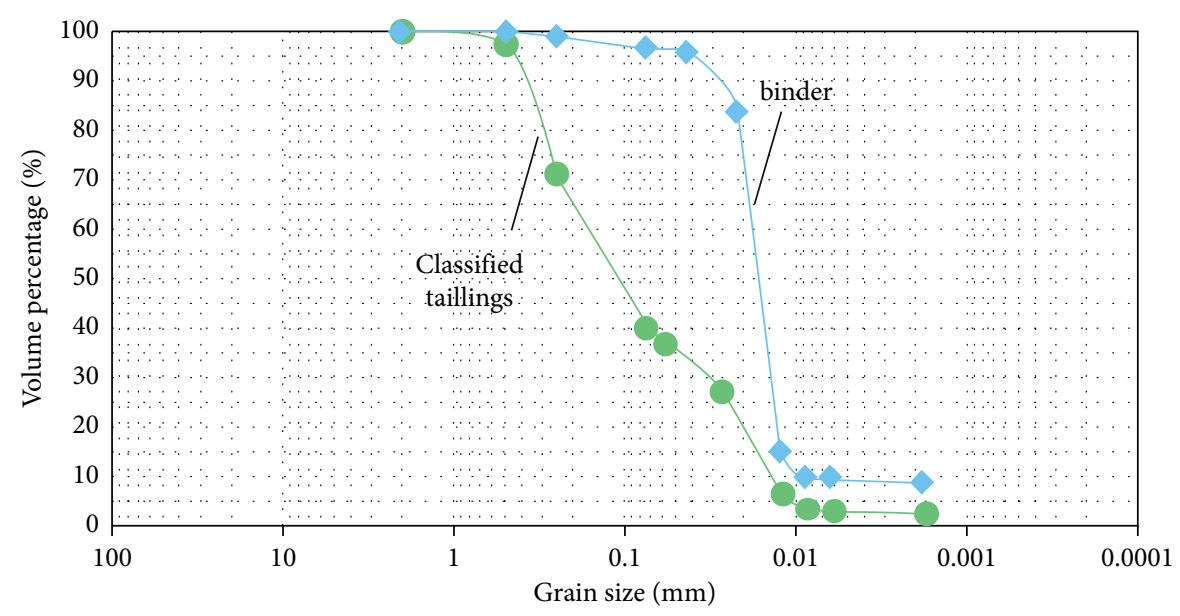

FIGURE 1: Grain size distribution curves of the backfill material.

(3) The leaching test results of heavy metals in tailing samples are shown in Table 3. It can be seen that the content of beneficial components and harmful components in the backfill material accounts for a relatively low proportion, so the backfill material can be selected as the backfill aggregate.

2.3. Proportion Test. To investigate the effect of consolidation characteristics and strength index on the backfill mixture with different binder proportions, tailing/slag ratios, and solid cement, five groups of paste-like samples were prepared with different proportions. The standard test moulds were then made [12-14]. After that, five groups of paste-like samples were ground into smooth parallel surfaces for UCS and TS testing [14-17]. All of the experimental values of UCS and TS tests are presented in Table 4. The weight and bleeding rate of the backfilling slurry are shown in Table 5, and the slump test results are listed in Table 6.

(1) Table 4 clearly shows that when the backfilling body (cement: binder : classified tailings) of $1: 4: 6$ or $1: 4: 8$ has a mass fraction of $70 \%-78 \%$, the uniaxial compressive strength at 28 days is more than $1.6 \mathrm{MPa}$. Similarly, when the filling ratio is $1: 4: 15$ and the mass fraction is $70 \% \sim 78 \%$, the $28 \mathrm{~d}$ uniaxial compressive strength is more than $0.6 \mathrm{MPa}$. It shows that the strength of the filling body can meet the requirements of the filling mining method.

(2) It can be seen from Table 5 that, compared with the general backfilling materials with the bleeding rate of $4 \% \sim 9 \%$, the slump of filling slurry of $1: 4: 8$ or $1: 4$ : 15 is greater than the specified value of $160 \mathrm{~mm}$, and the bleeding rate of filling slurry is about $2 \% \sim 4 \%$, indicating that the filling slurry has good rheology and is conducive to slurry transportation, and the curing water performance of the backfilling body has been significantly improved. Therefore, the backfilling slurry is called paste slurry.

(3) Considering some of the economic and technological factors of the flowing pipeline transportation, it is recommended that the optimal ratio of backfilling (cement:binder:classified tailings) is $1: 4: 8$, the mass fraction is $74 \%-76 \%$, and the uniaxial compressive strength is approximately $1.5 \mathrm{MPa}$ within 28 
TABLE 3: Leaching test results of heavy metals in tailings samples.

\begin{tabular}{|c|c|c|c|c|c|c|c|c|}
\hline \multirow{2}{*}{ Sample number } & \multicolumn{8}{|c|}{ Analysis items and content $(\mathrm{mg} / \mathrm{L})$} \\
\hline & $\mathrm{Cu}$ & $\mathrm{Zn}$ & $\mathrm{Cd}$ & $\mathrm{Pb}$ & Cr6+ & $\mathrm{Cr}$ & Alkyl mercury & $\mathrm{Hg}$ \\
\hline XW-6 & 0.0726 & 1.8740 & 0.0071 & 0.0941 & 0.0048 & 0.0050 & Not detected & 0 \\
\hline XW-7 & 0.0728 & 1.8722 & 0.0071 & 0.0942 & 0.0049 & 0.0052 & Not detected & 0 \\
\hline XW-8 & 0.0721 & 1.8659 & 0.0072 & 0.0941 & 0.0047 & 0.0048 & Not detected & 0 \\
\hline XW-9 & 0.0699 & 1.8801 & 0.0070 & 0.0939 & 0.0046 & 0.0047 & Not detected & 0 \\
\hline XW-10 & 0.0730 & 1.8738 & 0.0071 & 0.0943 & 0.0048 & 0.0050 & Not detected & 0 \\
\hline Average & 0.0721 & 1.8739 & 0.0071 & 0.0941 & 0.0049 & 0.0049 & Not detected & 0 \\
\hline
\end{tabular}

TABLE 4: Results of laboratory tests of cemented classified tailings.

\begin{tabular}{|c|c|c|c|c|c|c|c|c|}
\hline \multirow[b]{2}{*}{ No. } & \multirow{2}{*}{$\begin{array}{c}\text { Cement: } \\
\text { binder: } \\
\text { classified tailings }\end{array}$} & \multirow{2}{*}{$\begin{array}{l}\text { Mass fraction of } \\
\text { solid material (\%) }\end{array}$} & \multicolumn{3}{|c|}{$7 \mathrm{~d}$ uniaxial compressive strength } & \multicolumn{3}{|c|}{$28 \mathrm{~d}$ uniaxial compressive strength } \\
\hline & & & Strength $(\mathrm{MPa})$ & $\begin{array}{l}\text { Yield strength } \\
(\mathrm{MPa})\end{array}$ & $\begin{array}{c}\text { Modulus of } \\
\text { elasticity }(\mathrm{MPa})\end{array}$ & $\begin{array}{l}\text { Strength } \\
(\mathrm{MPa})\end{array}$ & $\begin{array}{l}\text { Yield strength } \\
\quad(\mathrm{MPa})\end{array}$ & $\begin{array}{c}\text { Modulus of } \\
\text { elasticity }(\mathrm{MPa})\end{array}$ \\
\hline 1 & $1: 3: 6$ & 70 & 0.72 & 0.73 & 65.07 & 1.73 & 1.72 & 198.53 \\
\hline 2 & $1: 4: 6$ & 76 & 0.78 & 0.74 & 42.73 & 1.98 & 1.96 & 202.57 \\
\hline 3 & $1: 4: 6$ & 78 & 0.81 & 0.81 & 38.74 & 2.04 & 2.04 & 201.13 \\
\hline 4 & $1: 4: 8$ & 70 & 0.50 & 0.49 & 40.55 & 1.61 & 1.51 & 199.02 \\
\hline 5 & $1: 4: 8$ & 76 & 0.62 & 0.59 & 41.02 & 1.64 & 1.59 & 195.38 \\
\hline 6 & $1: 4: 8$ & 78 & 0.65 & 0.65 & 28.52 & 1.80 & 1.80 & 202.88 \\
\hline 7 & $1: 4: 10$ & 70 & 0.35 & 0.36 & 26.99 & 1.24 & 1.24 & 125.48 \\
\hline 8 & $1: 4: 10$ & 76 & 0.38 & 0.42 & 24.55 & 1.33 & 1.29 & 145.46 \\
\hline 9 & $1: 4: 10$ & 78 & 0.52 & 0.54 & 14.32 & 1.44 & 1.42 & 175.67 \\
\hline 10 & $1: 4: 15$ & 70 & 0.27 & 0.26 & 23.22 & 0.64 & 0.58 & 39.52 \\
\hline 11 & $1: 4: 15$ & 76 & 0.33 & 0.31 & 25.66 & 0.69 & 0.69 & 37.76 \\
\hline 12 & $1: 4: 15$ & 78 & 0.38 & 0.35 & 14.74 & 0.80 & 0.80 & 53.83 \\
\hline 13 & $1: 4: 18$ & 70 & 0.25 & 0.27 & 15.62 & 0.36 & 0.33 & 29.92 \\
\hline 14 & $1: 4: 18$ & 76 & 0.29 & 0.31 & 13.31 & 0.39 & 0.41 & 35.34 \\
\hline 15 & $1: 4: 18$ & 78 & 0.34 & 0.33 & 11.24 & 0.45 & 0.44 & 40.36 \\
\hline
\end{tabular}

TABLE 5: The weight and bleeding rate of the backfilling slurry.

\begin{tabular}{lcccc}
\hline No. & Cement $:$ binder : classified tailings & Mass fraction $(\%)$ & Weight $\left(\mathrm{t} / \mathrm{m}^{3}\right)$ & Bleeding rate $(\%)$ \\
\hline 1 & $1: 4: 8$ & 70 & 1.94 & 4.52 \\
2 & $1: 4: 8$ & 76 & 1.9 & 3.14 \\
3 & $1: 4: 8$ & 78 & 1.93 & 2.26 \\
4 & $1: 4: 15$ & 70 & 1.91 & 3.41 \\
5 & $1: 4: 15$ & 76 & 1.87 & 3.23 \\
6 & $1: 4: 15$ & 78 & 1.88 & 2.75 \\
\hline
\end{tabular}

TABLE 6: The values of the slump and slump spread of the backfilling slurry.

\begin{tabular}{|c|c|c|c|c|c|c|}
\hline \multirow{2}{*}{$\begin{array}{l}\text { Cement: binder: } \\
\text { classified tailings }\end{array}$} & \multirow[b]{2}{*}{ Mass fraction (\%) } & \multicolumn{2}{|c|}{ Degree of slump (cm) } & \multicolumn{2}{|c|}{ Slump proliferation $(\mathrm{cm})$} & \multirow{2}{*}{$\begin{array}{l}\text { Slump proliferation/ } \\
\text { degree of slump }\end{array}$} \\
\hline & & $\begin{array}{c}\text { Actual } \\
\text { measurement }\end{array}$ & Average & $\begin{array}{c}\text { Actual } \\
\text { measurement }\end{array}$ & Average & \\
\hline \multirow{3}{*}{$1: 4: 8$} & & 21.5 & & 65.4 & & \\
\hline & 76 & 21.7 & 21.6 & 65.6 & 65.50 & 3.0 \\
\hline & & 21.6 & & 65.5 & & \\
\hline \multirow{3}{*}{$1: 4: 15$} & & 20.2 & & 66.4 & & \\
\hline & 76 & 20.4 & 20.4 & 66.5 & 66.40 & 3.25 \\
\hline & & 20.6 & & 66.3 & & \\
\hline
\end{tabular}


days. Further, the best proportion of the recommended vacuum area is $1: 4: 15$, and its corresponding mass fraction and the single-axis compressive strength of 28 days are $74 \%$ to $76 \%$ and $0.6 \mathrm{MPa}$, respectively.

(4) Table 6 shows that the rheological properties are very important characteristics, showing the flowing ability of the backfill mixture of slurry by gravity or outside force and the degree of backfill in underground mined voids, including the degree of slump, slump proliferation, and a diffusibility-to-slump ratio. The slump test of the backfill material shows that the average degree of slump is more than $21.6 \mathrm{~cm}$, belonging to T4 grade, which conduces to pipeline transportation. Slump proliferation was more than $65.50 \mathrm{~cm}$, which shows that the backfill mixture of the slurry has good flowing ability. The diffusibility-to-slump ratio varied from 3.0 to 3.25 , which meets the requirement of preparation and transportation. Therefore, the rheological properties of backfill slurry with the suggested dosage are similar to cemented paste backfill slurry, called "paste" slurry. The paste has the characteristics of low bleeding rate and high slurry saturation rate.

\section{Circular Pipe Test}

3.1. Pumping Test. The pumping of backfilling slurry has always been a very complex process in the filling system, involving complex parameters [18-20]. Therefore, the circular pipe test is needed to ensure the stability and reliability of the filling system $[21,22]$.

According to the relevant research results of filling pumps at home and abroad $[23,24]$ and the design of the backfilling system of HCM, a seamless steel pipe with an inner diameter of $100 \mathrm{~mm}$ and a thickness of $7 \mathrm{~mm}$ and a piston backfilling pump, namely, HBT80/21-220s, are used for the test of graded tailings conveying circulating pipeline. It also includes other equipment, such as a speedometer, two pressure sensors, and some bends with a bending radius of $600 \mathrm{~mm}$ and a bending angle of $90^{\circ}$. The pipeline is connected by a quick connector, and the outlet of the filling pump is connected by a reducing pipe (thickness $7 \mathrm{~mm}$ and length $400 \mathrm{~mm}$ ). According to the characteristics of the mine filling system, the pipeline is laid horizontally, with a total length of about $120 \mathrm{~m}$, including the length of the horizontal pipe, reducer, and elbow. The layout of the test is shown in Figure 2.

In order to ensure the uniformity and rationality of the backfilling slurry, the slurry is prepared by manual feeding and metering. Three $0.75 \mathrm{~m}^{3}$ concrete mixers are used for uniform mixing, and the mixing time is required to be 5 to 6 minutes.

As the charge pump moves back and forth in operation, the flow rate of the charge slurry fluctuates randomly. Therefore, it is of no value to determine the flow rate of backfilling slurry in this loop test. Therefore, the piston filling pump of hgbs80.21.220 shall operate at 13 times/min so that the flow of backfilling slurry can be guaranteed at $50 \mathrm{~m}^{3} / \mathrm{h}$.
Considering that the filling ratio of cement cemented graded tailings is $1: 4: 15$, it is easier to transport through the pipeline than the filling material of $1: 4: 8$. Therefore, the pumpability test of filling slurry was carried out with the filling ratio of $1: 4: 8$ and the filling slurry concentration of $76 \%$. In addition, on the premise that the filling flow is $50 \mathrm{~m}^{3} / \mathrm{h}$, the pressure value of the inlet and outlet pipelines is measured at the following three times: start the pump, restart the pump after stopping for 20 minutes, and restart the pump after stopping for 1 hour. Therefore, the results are shown in Figures 3-5, where P1 and P2 are the values of test points 1 and 2 , respectively, and $\mathrm{dp} 1=p_{1}-p_{2}$, and $p^{*}$ represents the average value of $p$.

3.2. Result of Analysis. As can be seen from Figure 4 that, when the filling pump is started, the flow is $50 \mathrm{~m}^{3} / \mathrm{h}$, and the pressure loss of $100 \mathrm{~m}$ long pipeline is about $0.4 \mathrm{MPa}$. Therefore, when the pipe length is $1691 \mathrm{~m}$, it will be assumed that the pressure loss is about $6.76 \mathrm{MPa}$, which is basically consistent with the horizontal pipe resistance of $6.76 \mathrm{MPa}$ calculated earlier. This shows that the calculated pipe resistance of the above ring pipe test is reasonable.

Figure 5 shows that if the filling pump is restarted after 20 minutes of shutdown, the pressure loss (about $0.7 \mathrm{MPa}$ ) increases significantly, indicating that the filling slurry still has a certain degree of settlement within 20 minutes, which will lead to the increase in pipeline pressure loss. Therefore, the filling pump can still provide pressure loss, indicating that the filling industrial pump meets the requirements of stable operation of the filling system.

It can be seen from the main pressure results in Figure 6 that the filling pump was restarted after it was stopped for 60 minutes, and the pressure loss of the pipeline exceeded 1.0 MPa. Through calculation, the pressure loss of $2000 \mathrm{~m}$ long pipeline exceeds $20 \mathrm{MPa}$, which cannot ensure the stability of the filling system. Therefore, the filling slurry in the filling pipeline needs to be discharged before restarting the filling pump.

\section{Backfill System}

The backfill system consists of backfilling material preparation and storage unit, backfilling material mixing unit, and conveying unit [25].

In recent years, dry sand bin is more and more widely used in China. Dry sand bin can be divided into vertical and horizontal sand bins. The sand is discharged by highpressure water injection for the vertical sand bin, while it is difficult to control the flow and concentration. The horizontal sand silo uses rakes to deliver sand, combining with the mechanical mixing system. Flow rates and concentrations are easily controlled. Undoubtedly, the horizontal sand silo is supposed to be applied in the Heiniudong copper mine (HCM) [26].

According to the requirements of the paste-like filling scheme, graded tailings are from the tailings of the concentrator, adhesives and other solid materials are from industrial waste, and cement is from cement plant [27]. Firstly, 


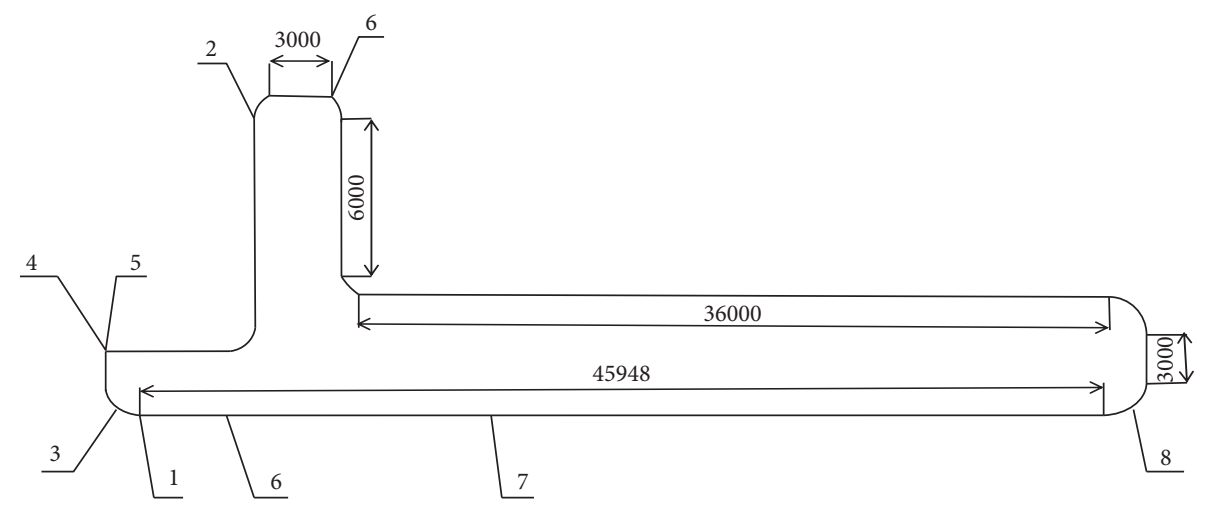

FIgURe 2: The layout of the circular pipe test. $1: p_{1} ; 2: p_{2} ; 3$ : velocity determination instrument; 4: HBT80/21-220s; 5: blender; 6: test position; 7: seamless steel pipe; 8: bend.

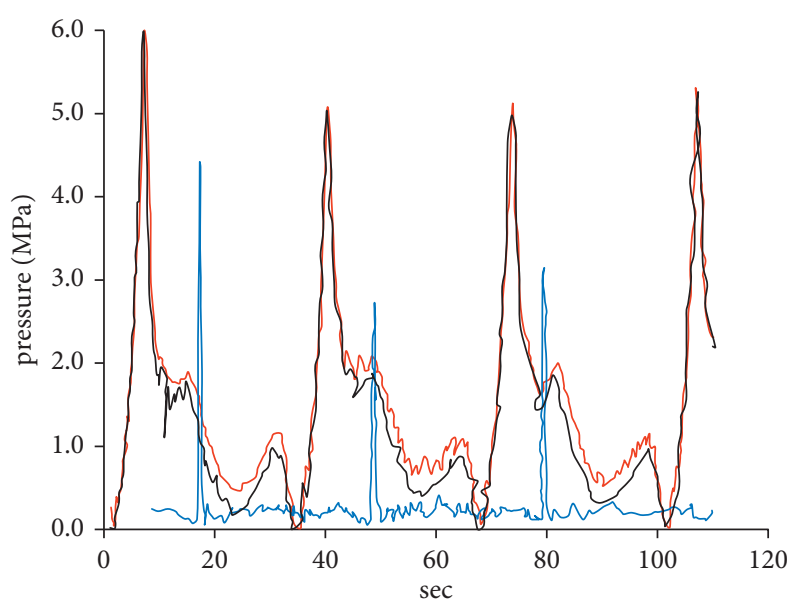

$$
\begin{aligned}
& -\mathrm{P} 1 \\
& -\mathrm{P} 2 \\
& -\mathrm{dp} 3
\end{aligned}
$$

Figure 3: The inlet and outlet pressure of activation.

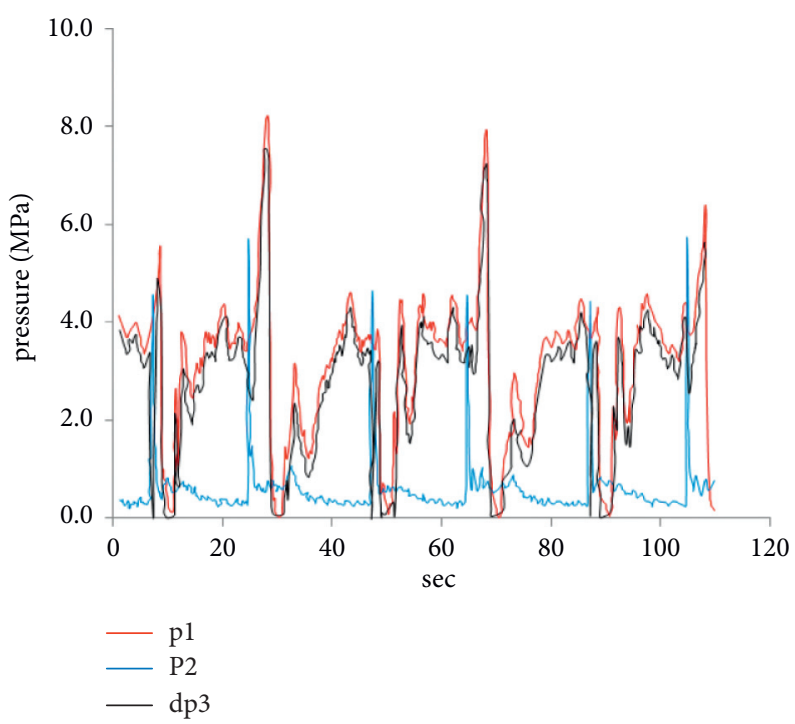

Figure 4: The inlet and outlet pressure of 20-minute restarting. 


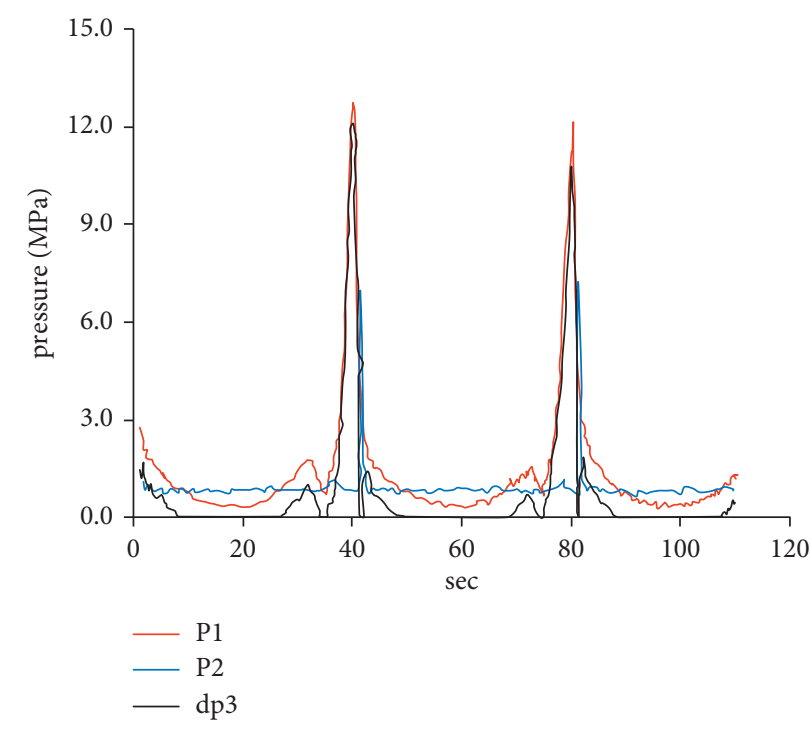

FIGURE 5: The inlet and outlet pressure of one-hour restarting.

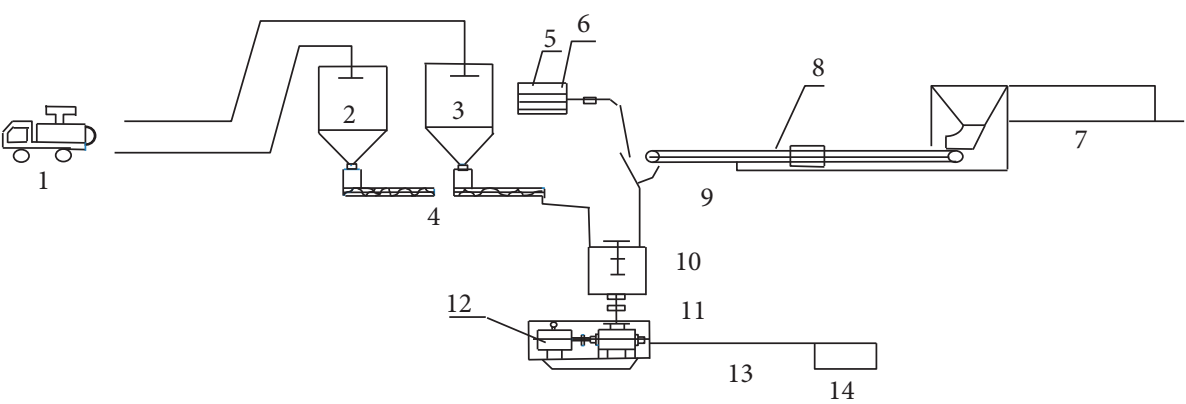

FIGURE 6: Backfill process: 1: tank; 2: cement storehouse; 3: binder storehouse; 4: spiral feeder; 5: high-seated field pond; 6: water; 7: horizontal sand silo; 8: belt conveyer; 9: hopper; 10: mixing tank; 11: densimeter; 12: backfilling pump; 13: pipeline; 14: stope.

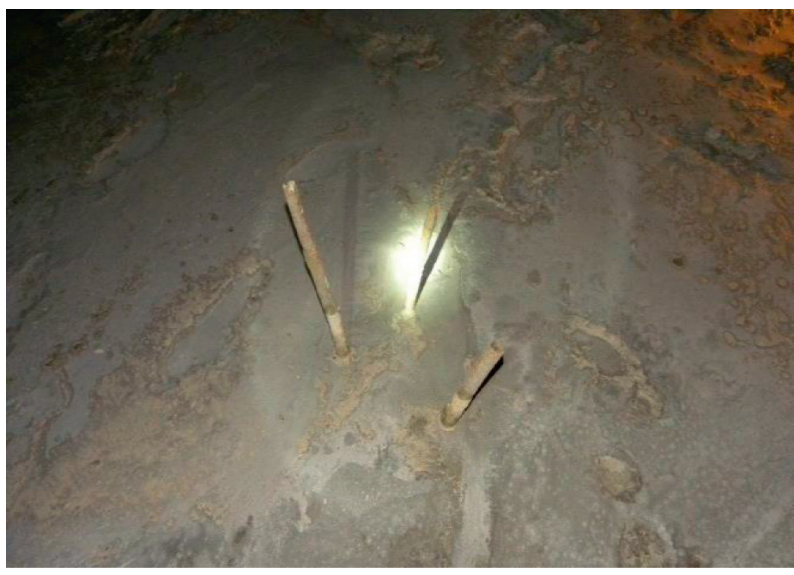

Figure 7: Backfill effect.

the unclassified tailings shall be deslimed and graded in the concentrator and then transported to the filling station.

The graded tailings are transported to the horizontal sand bin by belt conveyer, drained and sent to the storage room, and then sent to the mixing tank through the vibrating feeder fixed at the bottom of the warehouse. The backfilling water is added to the mixing tank through the high-seated field pond. The cement and adhesive are transported by the tank truck, unloaded into the vertical sand bin and adhesive bin, respectively, and then enter the 
mixing tank through the bottom spiral feeder. When classified tailings, binder, cement, and other solid materials are all conveyed into the mixing tank, several types of backfill material will be automatically mixed by a control system, with different feeding speeds of different materials. Afterwards, the mixed backfill material is directly transported to the working face of the stope through the pipeline by the high-pressure pump. The backfilling process is shown in Figure 6.

\section{Application Evaluation in HCM}

The feasibility of the mine backfilling system and backfilling process is verified by the backfilling industrial application. According to the industrial application of HCM, the results of the application show that the technology has the characteristics of low cost, large capacity, high recovery, good backfill effect, low accident, and environmental protection. The backfilling capacity of the backfilling process is $50 \mathrm{~m}^{3} / \mathrm{h}$ and $300 \mathrm{~m}^{3} / \mathrm{d}$, which shows that it can fully meet the production requirements.

The total investment of the backfilling system is about 10 million yuan, of which the mass fraction of backfilling slurry is $76 \%$, and the backfilling cost is $63.68 \mathrm{yuan} / \mathrm{m}^{3}$ or 25.56 yuan/t. In addition, HCM can improve the overall recovery rate of mine residual ore by the filling method. It is estimated that 1,07,459 tons of copper can be recovered, with a value of 1.28 billion yuan. According to the current market price of the copper mine, it is about 12,000 yuan per ton. Furthermore, the land occupation of classified tailings decreases obviously, and the tailing dam management becomes easier. The backfilling mining can meet the requirements of environmental protection policies and produce more economic benefits.

It can be seen from Figure 7 that the contact roof filling effect is large, and the roof subsidence is only $1.32 \mathrm{~mm}$, indicating that the pulp is densely distributed around the stope boundary, and the average compressive strength is 1.5 MPa, which improves the safety of mining. Therefore, it is feasible and reasonable to adopt the paste pumping and backfilling system with paste-like long-distance transportation and high stowing gradient in cold and high-altitude areas.

\section{Conclusion}

(1) According to the physical and chemical characteristics of HCM backfilling material, the particle size distribution range of the material is large, the grading is good, the content of useful minerals in tailings is small, and the content of harmful substances unfavorable to backfilling is very low. It is suitable for full tailings to be used as underground backfilling.

(2) According to the proportion test, the recommended optimum proportion (cement: binder: graded tailings) of stope and goaf is $1: 4: 8$ and $1: 4: 15$, respectively, and the mass fraction is $74 \%$ 76\%. The strength of the backfilling body meets the backfilling requirements.
(3) Through the circular pipe experiment, the backfilling pump, with the minimum pressure $13 \mathrm{MPa}$ being afforded, is capable of meeting the requirements of the whole backfill system as the maximum pressure loss of the $2000 \mathrm{~m}$ long pipeline is 6-8 MPa when the flow rate is $50 \mathrm{~m}^{3} / \mathrm{h}$.

(4) The technology introduced in this paper provides reference mining experience for the similar mines in terms of the backfill system in shallow as the application of new paste-like pumping technology with long distance and high stowing gradient at HCM is the successful case in China so far, especially in cold and high-altitude areas.

\section{Data Availability}

The data used to support the findings of this study are available from the corresponding author upon request.

\section{Additional Points}

Highlights. (1) A paste pipeline transportation of backfill pumping technology with long-distance and high stowing gradient is proposed in cold and high altitude area. (2) The circular pipe experiment was studied in the laboratory and outdoor. (3) The backfill system analysis evaluation were studied in the laboratory and outdoor. (4) The feasibility of mine backfilling system and backfilling process is verified by backfilling industrial application.

\section{Conflicts of Interest}

The authors declare that they have no conflicts of interest.

\section{Acknowledgments}

This research was funded by the Project 2013BAB02B05 and the National Social Science Foundation of China. 2013BAB02B05.

\section{References}

[1] S. Yin, W. Aixiang, K. Hu, Y. Wang, and Y. Zhang, "The effect of solid components on the rheological and mechanical properties of cemented paste backfill," Minerals Engineering, vol. 35, pp. 61-66, 2012.

[2] T. Igarashi and T. Oyama, "Deterioration of water quality in a reservoir receiving pyrite-bearing rock drainage and its geochemical modeling," Engineering Geology, vol. 55, no. 1-2, pp. $45-55,2000$.

[3] M. Fall and J. C. Célestin, "A contribution to understanding the effects of curing temperature on the mechanical properties of mine cemented tailings backfill," Engineering Geology, vol. 114, no. 4, pp. 397-413, 2010.

[4] K.-H. Xiong and S.-Y. Lin, "The experimental study on preparing binding material with coal gangue," Shanxi Architecture, vol. 35, no. 20, pp. 172-173, 2009.

[5] P. K. Senapati and B. K. Mishra, "Design considerations for hydraulic backfilling with coal combustion products (CCPs) at high solids concentrations," Powder Technology, vol. 229, pp. 119-125, 2012. 
[6] Q. Lin, P. Cao, G. Wen, J. Meng, R. Cao, and Z. Zhao, "Crack coalescence in rock-like specimens with two dissimilar layers and pre-existing double parallel joints under uniaxial compression," International Journal of Rock Mechanics and Mining Sciences, vol. 139, Article ID 104621, 2021.

[7] W. Aixiang, Y. Shenghua, W. Hongjiang, Q. Wenqin, and Q. Guanzhou, "Technological assessment of a mining-waste dump at the Dexing copper mine,China, for possible conversion to an in situ- bioleaching operation," Bioresource Technology, vol. 100, pp. 1931-1936, 2009.

[8] M. Benzaazoua, B. Bussière, I. Demers, M. Aubertin, É. Fried, and A. Blier, "Integrated mine tailings management by combining environmental desulphurization and cemented paste backfill: application to mine Doyon, Quebec, Canada," Minerals Engineering, vol. 21, no. 4, pp. 330-340, 2008.

[9] X.-M. Wang, B. Zhao, C.-S. Zhang, and Q.-L. Zhang, "Pastelike self-flowing transportation backfilling technology based on coal gangue," Mining Science and Technology, vol. 19, pp. 137-143, 2009.

[10] M. A. Rahman, M. Imteaz, A. Arulrajah, and M. M. Disfani, "Suitability of recycled construction and demolition aggregates as alternative pipe backfilling materials," Journal of Cleaner Production, vol. 66, no. 1, pp. 75-84, 2014.

[11] Q. Lin, P. Cao, R. Cao, H. Lin, and J. Meng, "Mechanical behavior around double circular openings in a jointed rock mass under uniaxial compression," Archives of Civil and Mechanical Engineering, vol. 20, no. 1, p. 19, 2020.

[12] M. Fall and S. S. Samb, "Effect of high temperature on strength and microstructural properties of cemented paste backfill," Fire Safety Journal, vol. 44, pp. 642-651, 2009.

[13] N. Roussel and P. Coussot, "“Fifty-cent rheometer" for yield stress measurements: from slump to spreading flow," Journal of Rheology, vol. 49, no. 3, pp. 705-718, 2005.

[14] S. Clayton, T. G. Grice, and D. V. Boger, "Analysis of the slump test for on-site yield stress measurement of mineral suspensions," International Journal of Mineral Processing, vol. 70, no. 1-4, pp. 3-21, 2003.

[15] N. Tregger, A. Gregori, L. Ferrara, and S. Shah, "Correlating dynamic segregation of self-consolidating concrete to the slump-flow test," Construction and Building Materials, vol. 28, pp. 499-505, 2012.

[16] J. Gao and A. Fourie, "Spread is better: an investigation of the mini-slump test," Minerals Engineering, vol. 71, no. 71, pp. 120-132, 2015.

[17] B. Sivakumar and T. M. Fernando, "Rive flowforecasting: use of phase space reconstruction and artificial neural net-works approaches," Journal of Hydrology, vol. 265, pp. 225-245, 2002.

[18] O. Nasir and M. Fall, "Modeling the heat development in hydrating CPB structures," Computers and Geotechnics, vol. 36, no. 7, pp. 1207-1218, 2009.

[19] H.-R. Wang, X.-B. Li, and G.-Y. Zhao, "Study on the parameters and resistance of low-elevation long-distance backfilling pipeline network," Metal Mine, vol. 39, no. 10, pp. 77-81, 2009, (in Chinese).

[20] Q. Lin, P. Cao, J. Meng, R. Cao, and Z. Zhao, "Strength and failure characteristics of jointed rock mass with double circular holes under uniaxial compression: insights from discrete element method modelling," Theoretical and Applied Fracture Mechanics, vol. 109, Article ID 102692, 2020.

[21] W. Guo, H. Dong, M. Lu, and X. Zhao, "The coupled effects of thickness and delamination on cracking resistance of X70 pipeline steel," International Journal of Pressure Vessels and Piping, vol. 79, no. 6, pp. 403-412, 2002.
[22] C. C. Clark, J. D. Vickery, and R. R. Backer, "Transport of total tailings paste backfill:result of full-scale pipe test loop pumping tests," Report of Investigations 9573, Report of investigations, Washington, DC, USA, 1995.

[23] A. C. S. Monterio and P. K. Bansal, "Pressure drop characteristics and rheological modeling of ice slurry flow in pipes," International Journal of Refrigeration, vol. 33, no. 8, pp. 1523-1532, 2010.

[24] D. P. Richard, "Flow velocities in pipelines," Journal of Hydraulic Engineering, vol. 109, no. 8, pp. 107-111, 1983.

[25] X. Peng, X.-B. Li, Q.-L. Zhang, and X.-M. Wang, "Quality evaluation of layerlike backfilling and flow pattern of backfill slurry in stope," Journal of Central South University of Technology, vol. 14, no. 4, pp. 580-583, 2007.

[26] X.-M. Wang, B. Zhao, and Q.-L. Zhang, "Cemented backfill technology based on phosphorous gypsum," Journal of Central South University of Technology, vol. 16, no. 2, pp. 285-291, 2009.

[27] F. Ju, J. Zhang, and Q. Zhang, "Vertical transportation system of solid material for backfilling coal mining technology," International Journal of Mining Science and Technology, vol. 22, no. 1, pp. 41-45, 2012. 